\title{
Influence of Age, Sex, Height and Lumber Stenosis on the Position of the Conus Medullaris in Adults
}

\author{
Influencia de la Edad, Sexo, Altura y Estenosis Lumbar \\ en la Posición del Cono Medular en Adultos
}

Khasawneh, R. R.

KHASAWNEH, R. R. Influence of age, sex, height and lumber stenosis on the position of the conus medullaris in adults. Int. J. Morphol., 37(3):867-871, 2019.

SUMMARY: Anatomical orientation of the termination level of Conus Medullaris (CM) has imperative role clinically for anesthetists and neurosurgeons which is considered as an objective guide to perform spinal anesthesia and spinal punctures circumspectly with less chance to have serious injuries. The current retrospective study was carried on to determine the location of the CM and how its termination level can be influenced by age, sex, height and lumber stenosis spine disease. The study included 462 participants that consisted of 199 men and 263 women range from 21 to 80 years of age and height range between $150-190 \mathrm{~cm}$. Also, it included 150 lumber stenosis patients. The location of the CM was imaged using a series of magnetic resonance images (MRI) for the lumbosacral spine at different levels including, T12, T12-L1, L1, L1-L2, and L2. The measurements revealed inconsiderable differences in the CM termination level in relation to age, sex and height in a healthy study population. Moreover, the results showed insignificant differences in the CM termination level between men and women whether they are healthy or having lumbar spinal stenosis. In conclusion, the most common level of CM termination is at L1 followed by L1-L2. It is safe to perform a lumbar neuraxial procedures at the level of L3-L4.

KEY WORDS: Conus medullaris; Magnetic Resonance Imaging; Age; Gender; Lumbar spinal stenosis.

\section{INTRODUCTION}

Conus Medullaris, is the last segment of the spinal cord from which the lumbosacral nerve roots protrude (Wilson \& Prince, 1989). It is terminated at a level extending from T12 to L3 (Barson, 1970; Wilson \& Prince; Zalel et al., 2006). Based on the rule of thumb the CM termination level can have normal range of morphological measurements variation. However, the factors that may manipulate the CM position after attaining its final level remain controversially unpredictable and widely distributed.

Determining CM position is considered of great clinical importance in diagnosis of tethered cord syndrome, spinal anesthesia, myelography and lumber punctures (Demiryürek et al., 2002). Misleading CM termination level prior to serious clinical procedures such as neuraxial and peripheral nerve blocks leads to failure in achieving their therapeutic objectives or in the worst scenario results in severe complications. Direct traumas to the spinal cord could occur if the needle is inserted too deeply at higher vertebral levels. Although this is a rare complication, as most punctures are carried out inferior to the CM position (Patel, 2009;
Fischer, 2012), the lack of knowledge regarding surface anatomy and imprecise needle insertion could cause spinal cord injury that can end up with paralysis (Absalom et al., 2001). Moreover, it is obligatory to know the termination level of CM in order to accurately aid in proper diagnosis of low lying tethered cord in children (Snider et al., 2008). This means that safe and flawless practicing of clinical procedures can be achieved by acquiring the habit of improving and updating our knowledge of structural anatomy and rummaging for new techniques that can help in accurately determining the exact anatomical positions which can reduce the adverse effects of many surgical and diagnostic approaches. In this light, the purpose of this study was to investigate the position of the CM by retrospectively reviewing large series of MRIs images, and correlate the termination position of CM with age, sex, and height in healthy population. Furthermore, the position of CM was determined in patient with lumber stenosis, and then we compared the control healthy group findings in correspondence to lumbar stenosis patients group in order to assess the effect of spine diseases on the position of the

Department of Basic Medical Sciences, Faculty of Medicine, Yarmouk University, Irbid, Jordan. 
CM. The current study aimed to help in providing a new direction for appropriate selection of intervertebral space to perform the lumbar puncture procedure safely and to minimize the risk of spinal cord injury during serious operations, like neuraxial procedure. Also, this study gave strong insights by finding the possible effects of spine remodeling diseases on the $\mathrm{CM}$ termination level.

\section{MATERIAL AND METHOD}

Study sample: This study included participants from King Abdullah University hospital, who had been referred for MRI imaging to assess the possible causes of low back pain for the past two years. Individuals with a history of fractures, dislocation or surgeries in the vertebral column or spinal cord were excluded from the study. The total study sample consisted of 612 individuals with ages ranging from 21 to 80 years of age. Among the study subjects, 199 were healthy males and 263 were healthy females. Also, the study group included 150 patients with lumbar stenosis ( 92 males and 58 females). All patients were required to meet the following criteria: no past or current history of tumor, trauma, or transitional vertebrae on the lumbar spine; no scoliosis or deformity; low back pain (including bilateral/unilateral radiating neurological signs such as sciatica, paresthesia, or numbness) or other clinical symptoms caused by lumbar spinal stenosis. The healthy male and female individuals were further classified into two age subgroups; the young adult's age group (21-50 years), and the elderly age group (51-80 years).

In order to study the effect of the height the 462 healthy subjects were also divided into three subgroups: first group height range was 151-160 cm; second group height range was $161-170 \mathrm{~cm}$, and third group height range was $171-180 \mathrm{~cm}$.
MRI imaging measurements: T1 and T2-weighted sagittal spin-echo MRIs of the lumbosacral spine were obtained for all studied individuals using 3-tesla MRI machine, the slice thickness was $4 \mathrm{~mm}$ for 462 of the subjects. The matrix was $256 \times 224$, with a $220 \mathrm{~mm}$ field of view. Observations were made on the DICOM files using the manufacture's software. The data was evaluated by two specialist radiologists, who were blind to the study design. The tip of the $\mathrm{CM}$ was defined as the most distal point of the spinal cord that could be visualized on the sagittal sequence (Fig. 1).

Statistical analysis: Data for CM termination level were categorized into 5 different levels. The association between $\mathrm{CM}$ termination level in healthy participants with correlation to age, sex, and height as well as the comparison between healthy participants and patients with lumbar stenosis were all tested using Pearson's chi-square test of association at 5 $\%$ level of significance.

\section{RESULTS}

The CM termination level in the 462 healthy subjects found to be located at the level of L1 with highest frequency (46.8\%), followed by L1-L2 as a second most common position $(20.1 \%)$ (Figs. 2A,B).

Variation in CM with age: The healthy subjects distributed into two different age groups as following: young adults (21-50 years) $\mathrm{n}=178$, and elderly group (51-80 years) $\mathrm{n}=284$. There was no noticeable association $(\mathrm{P}=0.24)$ between CM termination level and the age, however, the most common site of CM termination level in both age groups was L1 (Table I).
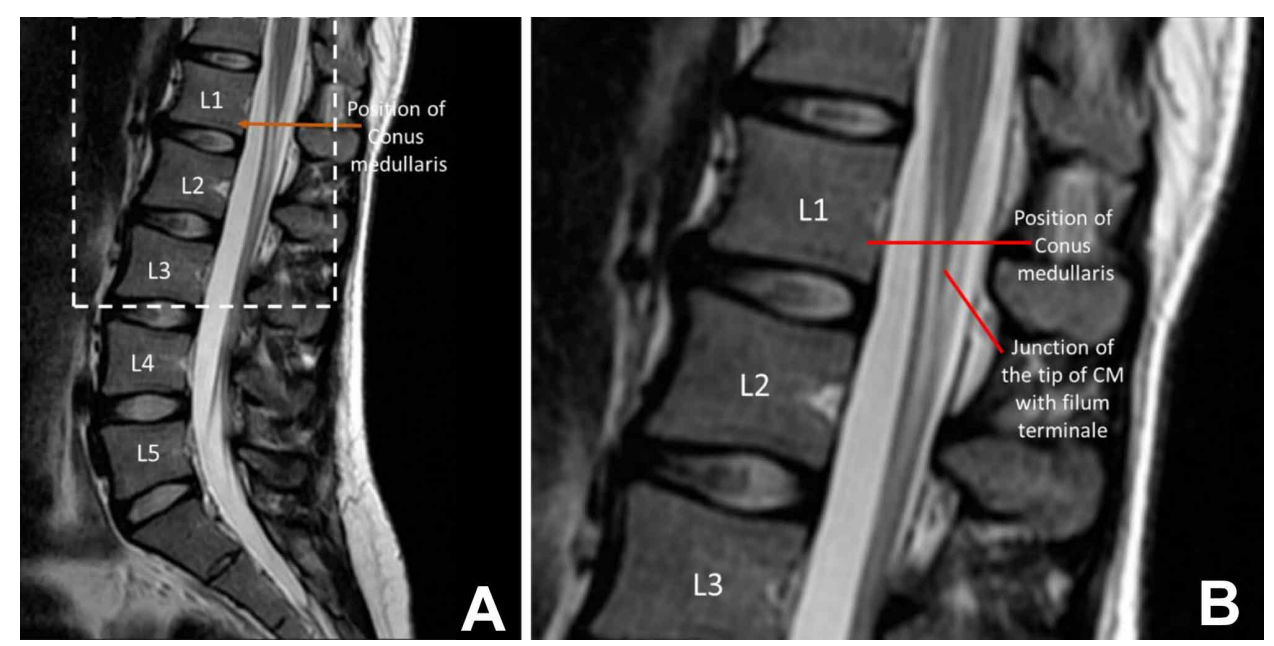

Fig. 1. Magnetic resonance image (MRI) demonstrating the method for determining the conus medullaris position, defined as the most distal point of the cord that can be visualized on the sagittal sequence. 


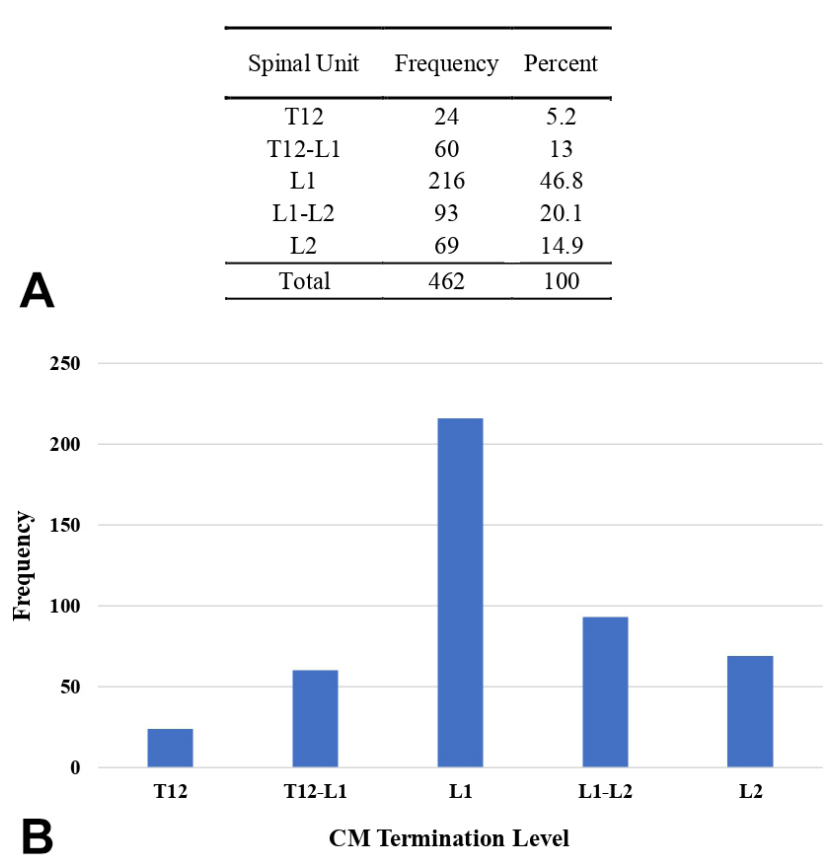

Fig. 2. General frequency of Conus Medullaris (CM) termination level among the healthy study group. (A) The table show the total number of the healthy subjects, the frequent distribution for the $\mathrm{CM}$ position according to the vertebral level, and the percentage for each group. (B) Graphic representation of the frequency of the CM termination level according to the vertebral level in the healthy study group

Table I. Distribution of conus medullaris levels with age.

\begin{tabular}{lccc}
\hline CM Level & $\begin{array}{c}\text { Adults } \\
(21-50 y)\end{array}$ & $\begin{array}{c}\text { Elderly } \\
(51-80 y)\end{array}$ & $\begin{array}{c}\text { P-value } \\
\left(\chi^{2}\right)\end{array}$ \\
\hline T12 & $12(6.7 \%)$ & $10(3.5 \%)$ & \\
T12-L1 & $22(12.3 \%)$ & $45(15.8 \%)$ & \\
L1 & $85(48.3 \%)$ & $109(38.4 \%)$ & 0.24 \\
L1-L2 & $35(19.7 \%)$ & $52(18.4 \%)$ & \\
L2 & $24(13.5 \%)$ & $68(23.9 \%)$ & \\
Total & 178 & 284 & 462 \\
\hline
\end{tabular}

Variation in CM with sex: The subjects were divided according to their gender as following: male group $n=199$ and female group $n=263$. There was no significant relation $(\mathrm{P}=0.71)$ between $\mathrm{CM}$ termination level and the gender of the participants. However, the most common site of CM termination level in both sexes was L1, followed by L1-L2 (Table II).
Table II. Distribution of Conus Medullaris levels with sex.

\begin{tabular}{lccc}
\hline CM Level & Male & Female & P-value $\left(\chi^{2}\right)$ \\
\hline T12 & $12(6.0 \%)$ & $12(4.6 \%)$ & \\
T12-L1 & $22(11.1 \%)$ & $38(14.4 \%)$ & \\
L1 & $92(46.2 \%)$ & $124(47.1 \%)$ & 0.71 \\
L1-L2 & $40(20.1 \%)$ & $53(20.2 \%)$ & \\
L2 & $33(16.6 \%)$ & $36(13.7 \%)$ & \\
Total & 199 & 263 & 462 \\
\hline
\end{tabular}

Variation in CM with height: The study subjects were further subdivided based on their height: 125 subjects with height range of 151-160 cm, 217 subjects with height range of $161-170 \mathrm{~cm}$, and 120 subjects with a height range of 171$180 \mathrm{~cm}$. There were no observed changes $(\mathrm{P}=0.35)$ in $\mathrm{CM}$ termination level weighed against participants height. However, the most common site of CM termination level in the three height groups was L1 as well (Table III).

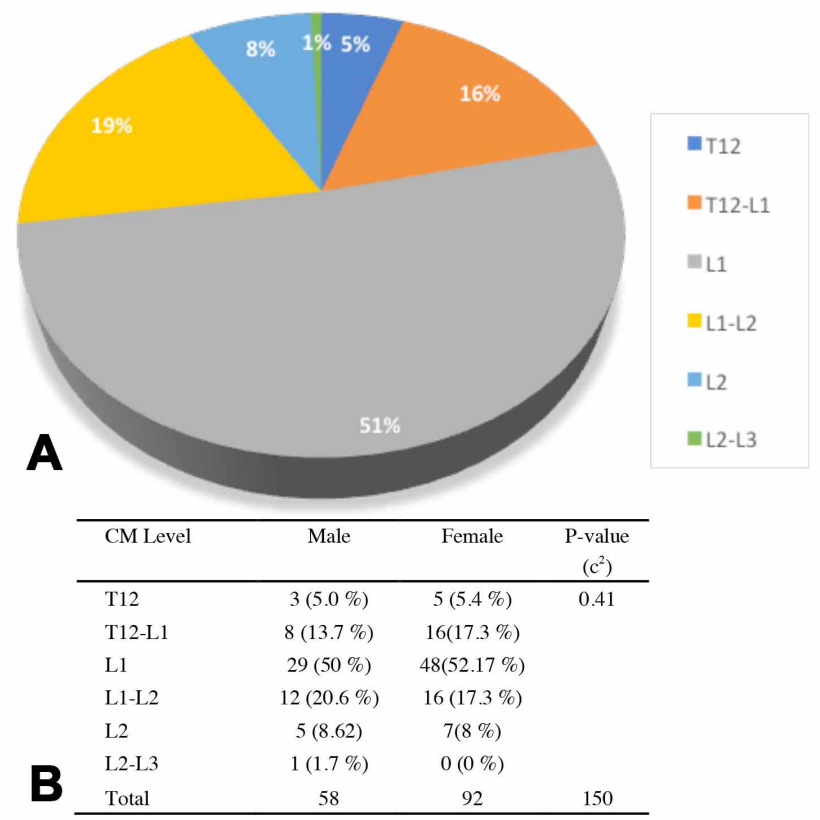

Fig. 3. Frequency distribution of Conus Medullaris in lumber stenosis patients. (A) A pie chart shows the precise Conus Medullaris position in patients with lumbar spinal stenosis. The CM located at the level of first lumber vertebra (L1) in $51 \%$ of the patients. (B) The table shows no significant difference $(\mathrm{P}=0.41)$ existed in conus medullaris position between men and women. $n=150$.
Table III. Distribution of Conus Medullaris levels with height.

\begin{tabular}{lcccc}
\hline CM Level & \multicolumn{3}{c}{ Height } & $\begin{array}{c}\text { P-value } \\
\left(\chi^{2}\right)\end{array}$ \\
\hline T12 & $751-160 \mathrm{~cm}$ & $161-170 \mathrm{~cm}$ & $171-180 \mathrm{~cm}$ & 0.53 \\
T12-L1 & $20(16.0 \%)$ & $9(4.1 \%)$ & $8(6.7 \%)$ & \\
L1 & $52(41.6 \%)$ & $114(52.5$ & $50(41.7 \%)$ & \\
L1-L2 & $25(20.0 \%)$ & $42(19.4 \%)$ & $26(21.7 \%)$ & \\
L2 & $21(16.8 \%)$ & $27(12.4 \%)$ & $21(17.5 \%)$ & \\
Total & 125 & 217 & 120 & 462 \\
\hline
\end{tabular}

The effect of lumber stenosis on the CM termination level: Investigating the $\mathrm{CM}$ position in 150 patients (58 males and 92 females) with lumber stenosis showed that $\mathrm{CM}$ termination level was at level of L1 which commensurate with findings in the healthy individuals (Fig. 3A). Moreover, there is no obvious variation existed in $\mathrm{CM}$ position between males and females with lumbar stenosis $(\mathrm{P}=0.41)$ (Fig. 3B). 


\section{DISCUSSION}

Variations in CM position can exist in normally developed adults due to asymmetric growth between the spinal cord and the vertebral column during normal fetal development. The position of CM ascends gradually from the sacral region during childhood to reach its adult position by 2 years of age and lies at frequent position of L1 to L2 (Wilson \& Prince; Zalel et al.). Knowledge of the exact position of CM level is essential before starting many procedures including lumber puncture and caudal injection to avoid the iatrogenic injury of spinal cord. This study is clinically of important relevance since it provides facts about the level of the spinal cord termination that is fundamentally should be known prior the initiation of lumber related procedures in patients.

Many previous studies were conducted to establish the determined conus termination level. The spinal cord in adults may terminate between the last thoracic and the third lumbar vertebra, but in most cases, it ends at the first or second lumbar vertebra (Barson). The location of CM termination according to age and sex was retrospectively evaluated (Kim et al., 2003; Soleiman et al., 2005) in different populations with MRI imaging system (Wilson \& Prince; Kim et al.; Ba et al., 2012). Some of these studies found trivial differences in the position of $\mathrm{CM}$ correlated with respect to age and sex of the studied subjects (Soleiman et al., 2005; Ba et al.).

The termination level of CM was significantly higher in male than female in a Korean adult's population (Kwon et al., 2016). Demiryürek et al. found a significant sex related differences in the mean of CM termination level in Turkish population based study, as it was found to be at T12-L1 level disc space in males, while in females it was seen at L1-L2 disc space. The race of the population might play a role in the sex allied differences of the CM termination position. In Koreans, Kim et al. used MR imaging to study the level of CM termination, he reported that the CM was positioned at L1-lower. Meanwhile, the $\mathrm{CM}$ termination level findings in Arabs based study indicated no significant age or sex associated differences in the mean of CM termination level as it was located mainly at L1-L2 disc in females and at lower level of L1 in males in different age groups (Nasr, 2017).

The effect of sex on the level of CM termination remains contentious despite that many studies have been conducted to confirm that. The results of the present study showed no significant sex related differences $(p>0.05)$ in the vertebral level of $\mathrm{CM}$ termination position as it was found to be at L1 in both male and female patients. This finding was consistent with several previous studies (Saifuddin et al., 1998; Macdonald et al., 1999; Demiryürek et al.; Moussallem et al., 2014).

The age of the subjects might be dubious factor that can affect the extent of the spinal cord (Hara, 1987). In our study; the results did not show any major correlation between the termination level of the CM and age that is consistent with a Nasr study.

The present study demonstrated that there is no effect of the person's height in the possible termination level of CM. Similarly, McCotter (1916) in 234 cases, reported that there was no connection between length of the human subject and CM termination level. In his study series, the level of the CM termination varied between the middle of T12 and the lower margin of L2, but in $77 \%$ of white males the cord termination was between the upper margin of L1 and L2. The utilization of sagittal MRI has given more reliable data about the determination of the conus position in living individuals which is considered currently as the ideal technique to determine the level of $\mathrm{CM}$ in patients with lumber spinal diseases (Qu et al., 2017). In the current study, MRI was used to report the $\mathrm{CM}$ termination level on patients with lumbar stenosis. Knowing the termination level of CM in patients with lumber stenosis is beneficial during lumber puncture, especially after a shocking incidence that was reported concerning the occurrence of paralysis following epidural puncture (Rahmani et al., 2011). The results indicated that the level of CM did not effected with lumber stenosis. Moreover, there is no significant difference in the level of $\mathrm{CM}$ between males and females with lumber stenosis as well as with those in control healthy groups, and the CM terminated mostly at level of L1. This outcome is going with the findings from earlier study which also reported that lumber stenosis did not affect the termination level of CM (Ba et al.).

Methodological, racial, and age differences among studies should be considered, this study is needed to further determine and corroborate the CM position controversy. Moreover, future studies are needed to determine whether the CM position will change due to other diseases. This study indicated that the tip level of the CM was not seen lower than the third lumbar vertebra. Therefore, findings of the present study strengthened and validated the previous reports which considered L3-L4 intervertebral disc space as reasonable and safe enough for performing the standard lumbar punctures regardless the age, sex and height parameters of the patients which have no influence on the CM termination level. 


\section{ACKNOWLEDGMENTS}

The study was funded by a grant from the Deanship of Research at Yarmouk University.

We would like to thank Dr. Mouhammed Z. Allouh and Dr. Ejlal Abu-El Rub for the time and effort spent in reviewing the Manuscript.

KHASAWNEH, R. R. Influencia de la edad, el sexo, la altura y la estenosis lumbar en la posición del cono medular en adultos. Int. J. Morphol., 37(3):867-871, 2019.

RESUMEN: La orientación anatómica del nivel de terminación del Conus medullaris (CM) tiene un importante papel clínico para los anestesistas y neurocirujanos, que se considera una guía objetiva para realizar la anestesia espinal y las punciones de la columna circunspectivamente con menos posibilidades de provocar lesiones graves. Se llevó a cabo un estudio retrospectivo para determinar la ubicación del CM y cómo su nivel de terminación puede verse afectado por la edad, el sexo, la altura y una patología de la columna vertebral, la estenosis lumbar. El estudio incluyó 462 participantes que consistían en 199 hombres y 263 mujeres de 21 a 80 años de edad y una altura de entre $150-190 \mathrm{~cm}$. Además, se incluyeron 150 pacientes con estenosis lumbar. La ubicación del CM se determinó mediante una serie de imágenes de resonancia magnética (RM) de la columna lumbosacra a diferentes niveles, incluidos T12, T12-L1, L1, L1-L2 y L2. Las mediciones revelaron diferencias considerables en el nivel de terminación de CM en relación con la edad, el sexo o la altura en una población de estudio saludable. Además, los resultados mostraron diferencias poco significativas en el nivel de terminación de CM entre hombres y mujeres, sanos o con estenosis espinal lumbar. En conclusión, se encontró que el nivel más común de terminación del CM es L1 seguido de L1-L2, considerándose seguro realizar procedimientos neuroaxiales lumbares a nivel de L3-L4.

PALABRAS CLAVE: Conus Medullaris; Resonancia magnética; Edad; Sexo; Estenosis de la columna lumbar.

\section{REFERENCES}

Absalom, A. R.; Martinelli, G. \& Scott, N. B. Spinal cord injury caused by direct damage by local anaesthetic infiltration needle. Br. J. Anaesth., 87(3):512-5, 2001.

Ba, Z.; Zhao, W.; Wu, D.; Huang, Y. \& Kan, H. MRI MRI study of the position of the Conus Medullaris in patients with lumbar spinal stenosis. Orthopedics, 35(6):e899-902, 2012.

Barson, A. J. The vertebral level of termination of the spinal cord during normal and abnormal development. J. Anat., 106(Pt. 3):489-97, 1970.

Demiryürek, D.; Aydingöz, U.; Aks, it, M. D.; Yener, N. \& Geyik, P. O. MR imaging determination of the normal level of Conus Medullaris. Clin. Imaging, 26(6):375-7, 2002.
Fischer, B. Techniques of epidural block. Anaesth. Intensive Care Med., 13(11):539-44, 2012.

Hara, K. Changes by age group in the caudal level of termination of the spinal cord in Japanese adults. Kaibogaku Zasshi, 62(4):329-33, 1987.

Kim, J. T.; Bahk, J. H. \& Sung, J. Influence of age and sex on the position of the Conus Medullaris and Tuffier's line in adults. Anesthesiology, 99(6):1359-63, 2003.

Kwon, K.; Kim, T.; Kim, S. \& Rhyu, I. The tip level of the Conus Medullaris by magnetic resonance imaging and cadaver studies in Korean Adults. Korean J. Phys. Anthropol., 29:47-51, 2016.

Macdonald, A.; Chatrath, P.; Spector, T. \& Ellis, H. Level of termination of the spinal cord and the dural sac: a magnetic resonance study. Clin. Anat., 12(3):149-52, 1999

McCotter, R. E. Regarding the length and extent of the human medulla spinaliS. Anat. Rec., 10(9):559-64, 1916.

Moussallem, C. D.; El Masri, H.; El-Yahchouchi, C.; Abou Fakher, F. \& Ibrahim, A. Relationship of the lumbar lordosis angle to the level of termination of the Conus Medullaris and thecal sac. Anat. Res. Int., 2014:351769, 2014.

Nasr, A. Y. Clinical relevance of Conus Medullaris and dural sac termination level with special reference to sacral hiatus apex: anatomical and MRI radiologic study. Anat. Res. Int., 92(4):456-67, 2017.

Patel, V. B. Techniques for epidural injections. Tech. Reg. Anesth. Pain Manag. 13(4):217-28, 2009.

Qu, Z.; Qian, B. P.; Qiu, Y.; Zhang, Y. P.; Hu, J. \& Zhu, Z. Z. Does the position of Conus Medullaris change with increased thoracolumbar kyphosis in ankylosing spondylitis patients? Medicine (Baltimore), 96(6); e5963, 2017.

Rahmani, M.; Vaziri Bozorg, S. M.; Esfe, A. R. G.; Morteza, A.; Khalilzadeh, O.; Pedarzadeh, E. \& Shakiba, M. Evaluating the Reliability of Anatomic Landmarks in Safe Lumbar Puncture Using Magnetic Resonance Imaging: Does Sex Matter? Int. J. Biomed. Imaging, 2011:868632, 2011.

Saifuddin, A.; Burnett, S. J. \& White, J. The variation of position of the Conus Medullaris in an adult population. A magnetic resonance imaging study. Spine (Phila Pa 1976), 23(13):1452-6, 1998.

Snider, K. T.; Kribs, J. W.; Snider, E. J.; Degenhardt, B. F.; Bukowski, A. \& Johnson, J. C. Reliability of Tuffier's line as an anatomic landmark. Spine (Phila Pa 1976), 33(6):E161-5, 2008.

Soleiman, J.; Demaerel, P.; Rocher, S.; Maes, S. \& Marchal, G. Magnetic resonance imaging study of the level of termination of the Conus Medullaris and the thecal sac: influence of age and gender. Spine (Phila Pa 1976), 30(16):1875-80, 2005.

Wilson, D. A. \& Prince, J. R. John Caffey award. MR imaging determination of the location of the normal Conus Medullaris throughout childhood. A. J. R. Am. J. Roentgenol., 152(5):1029-32, 1989.

Zalel, Y.; Lehavi, O.; Aizenstein, O. \& Achiron, R. Development of the fetal spinal cord: time of ascendance of the normal Conus Medullaris as detected by sonography. J. Ultrasound Med., 25(11):1397-401, 2006.

Corresponding author:

Ramada R. Khasawneh

Department of Basic Medical Sciences

Faculty of Medicine

Yarmouk University

Irbid

JORDAN

E-mail: Ramada@yu.edu.jo

Received: 04-02-2019

Accepted: 01-03-2019 